\title{
Rotavirus Infects Human Biliary Epithelial Cells and Stimulates Secretion of Cytokines IL-6 and IL-8 via MAPK Pathway
}

\author{
Maria Grazia Clemente, ${ }^{1,2}$ John T. Patton, ${ }^{3}$ Robert A. Anders, ${ }^{4}$ \\ Robert H. Yolken, ${ }^{5}$ and Kathleen B. Schwarz ${ }^{1}$ \\ ${ }^{1}$ Pediatric Liver Center, Johns Hopkins University School of Medicine, Baltimore, MD 21287, USA \\ ${ }^{2}$ Pediatric Clinic, Department of Surgery, Microsurgery and Medical Sciences, University of Sassari, 07100 Sassari, Italy \\ ${ }^{3}$ Virginia-Maryland Regional College of Veterinary Medicine, University of Maryland, College Park, MD 20742, USA \\ ${ }^{4}$ Department of Pathology, Johns Hopkins University School of Medicine, Baltimore, MD 21287, USA \\ ${ }^{5}$ The Stanley Division of Developmental Neurovirology, Johns Hopkins School of Medicine, Baltimore, MD 21287, USA
}

Correspondence should be addressed to Kathleen B. Schwarz; kschwarz@jhmi.edu

Received 25 March 2015; Revised 11 June 2015; Accepted 16 June 2015

Academic Editor: Keita Terui

Copyright (C) 2015 Maria Grazia Clemente et al. This is an open access article distributed under the Creative Commons Attribution License, which permits unrestricted use, distribution, and reproduction in any medium, provided the original work is properly cited.

\begin{abstract}
Biliary atresia (BA) is an infantile inflammatory cholangiopathy of unknown etiology although epidemiologic studies and animal models utilizing rotavirus (RV) have suggested a role for viral infection. Proinflammatory and profibrotic cytokines have been detected in infants with BA. The purpose of our study was to investigate the susceptibility of human cholangiocytes (H69 cells) to infection with RRV and to determine if this infection resulted in cytokine secretion. Infection of H69 cells by RRV was noncytolytic and resulted in a time-dependent increase in the release of both infectious virions and cytokines IL- 6 and IL- 8 into the supernate. The greatest difference in cytokine supernatant levels between infected and mock-infected cells was noted at 24 hours postinfection (h p.i.) for IL-8, $556 \pm 111$ versus $77 \pm 68 \mathrm{pg} / \mathrm{mL}$ ( $p<0.0001)$, and at $48 \mathrm{~h}$ p.i. for IL-6, $459 \pm 64$ versus $67 \pm 2 \mathrm{pg} / \mathrm{mL}(p<0.0001)$. Production of both cytokines following RRV infection was significantly reduced by pretreating the H69 cells with inhibitors of mitogen-activated protein kinase (MAPK). Conclusion. RRV can infect human cholangiocytes resulting in the production of proinflammatory and profibrotic cytokines via the MAPK pathway. RRV-infected H69 cells could be a useful model system for investigating the viral hypothesis of BA.
\end{abstract}

\section{Introduction}

Biliary atresia (BA) is a serious infantile liver disease of unknown cause, occurring in 1:5,000-1:20,000 live births [1]. We recently studied a group of $289 \mathrm{BA}$ infants enrolled in the Childhood Research and Education Network; 10\% had multiple congenital anomalies consistent with laterality defects and 6\% had multiple congenital anomalies not of the laterality type [1]. It is assumed that these two forms of BA begin prenatally and are probably genetic in origin [2]. Approximately $65-90 \%$ of BA cases are of the perinatal "acquired" type, the so-called "isolated" BA, not associated with major congenital anomalies $[1,3]$. Almost certainly the three forms of BA have different etiologies [1]. Given the characteristic time-space clustering and the expression of proinflammatory and profibrotic cytokines both in the liver and in the circulation, including interleukin-6 (IL-6) and interleukin-8 (IL-8), isolated BA is believed by some to be secondary to hepatobiliary viral infection $[3,4]$. IL-6 and IL8 are of particular interest since IL- 6 activates macrophages [5] and IL-8 attracts neutrophils [6] and both cell types are present abundantly around the cholangiocytes in the livers of isolated human BA [7, 8]. Huang et al. [9] showed that IL8 mRNA was increased in livers of BA patients compared to patients with choledochal cyst, both at the time of Kasai hepatic portoenterostomy and later, at the time of liver transplantation. Hepatic IL-6 mRNA was also increased in children in the late stage of BA [9].

Several viruses, including rotavirus (RV), have been implicated as causative agents of BA, but reports have been 
inconclusive [10]. Extensive investigations by several groups using RRV to induce BA in young mice have focused renewed attention on RV as an etiologic agent of BA [11]. RiepenhoffTalty et al. [12] first reported RV in hepatobiliary remnants of infants with BA, where they found that $50 \%$ of their cohort showed evidence of Group C RV infection [12]. These studies led to experiments which demonstrated that multiple animal RVs could infect Hep G2 liver carcinoma cells [13].

$\mathrm{RV}$ is the most common cause of infantile gastroenteritis worldwide, infecting virtually all children by 5 years of age [14]. Although the infection was initially thought to be restricted to the gastrointestinal tract, as RV requires trypsinlike proteases for activation, a number of authors have reported extraintestinal localization of RV in animal models, including RV antigenemia and recovery in multiple organs [15-17]. Furthermore Gilger et al. [18] reported that RV infection of the liver of newborn human infants with immunodeficiency is plausible, perhaps via dendritic cell infection as what has been shown in animal experiments [16]. BA is a rare disease and infants usually present with cholestasis, not with gastroenteritis. RV infection of newborns also is rare, ranging from 5 to $15 \%$, and it is asymptomatic in more than $90 \%$ of cases [19]. Thus the rarity of asymptomatic RV infection of the neonate combined with the fact that RV might infect the liver at least provides a logical basis for implicating RV in some cases of human BA.

Therefore, subsequent efforts were made to investigate snap frozen hepatobiliary remnants from children with BA for the presence of Groups A, B, and C RVs [20]. Failure to identify RV in any of these samples led to the conclusion that $\mathrm{RV}$ was not commonly involved in the etiology of acquired BA. However, it was later observed that, in mice infected with RRV on the first day of life, the virus cannot be detected in their liver at 2 weeks of age, when the hepatobiliary disease is evident [11], leading us to a reassessment of previous conclusions.

We recently studied the seroprevalence of Group A and Group C RV in infants with BA and cholestatic controls studied during the RV season in the United States (DecemberMay) in the pre-RV vaccine era. The overall prevalence of asymptomatic Group A RV infection found in our study was higher than the $5 \%$ previously published rates in this age group. It is of interest that, depending on the sensitivity of the assay used, $10-40 \%$ of infants with BA and $18-37 \%$ of cholestatic infants without BA did exhibit positive IgM for RV-A [21].

Jafri et al. [22] demonstrated that mouse cholangiocytes were susceptible to RV infection in vitro and that inhibition of the mitogen-activated protein kinase (MAPK) family signaling pathway reduced viral replication. Moreover, mouse cholangiocytes respond to RV infection by expressing chemokines in vitro, such as MCP-1, RANTES, KC, and MIP2 , some of which have been implicated in the pathogenesis of experimental BA [23]. More recently, the human cholangiocyte $\mathrm{H} 69$ cell line was also shown to be susceptible to RV infection in a way that paralleled the murine model of BA [24], providing a human in vitro model to further study the pathogenic mechanisms involved in human BA.
Here we show that the human cholangiocyte H69 cell line is susceptible to RV infection in vitro and that exposure of the cells to RRV induces the secretion of IL- 6 and IL-8, which have been associated with BA in humans. Inhibition of the MAPK family cell signaling pathway significantly reduced the secretion of these cytokines. We confirm that RV infection of human cholangiocytes can be a useful in vitro model for investigating the viral hypothesis of acquired BA in humans. Moreover, we provide clear evidence that human cholangiocytes in vitro can become immunoregulatory cells in response to virus infection.

\section{Materials and Methods}

2.1. Cells and Virus. Rhesus kidney epithelial MA104 cells (ATCC CRL-2378.1) were used to propagate RRV and were grown in Medium 199 containing 5\% (vol/vol) fetal bovine serum (FBS), 1\% penicillin/streptomycin, and 1\% Fungizone (Invitrogen, Carlsbad, CA). Human bile duct epithelial cells (H69 cell line, a biliary epithelial cell line produced from normal human liver) were kindly provided by Drs. N. La Russo and D. Jefferson and were grown as previously described [25].

Prior to infection, RRV was activated by incubation in Leibovitz medium (L-15, Invitrogen) containing $5 \mu \mathrm{g} / \mathrm{mL}$ of porcine trypsin (Sigma, St. Louis, MO) for 30 minutes (min) at $37^{\circ} \mathrm{C}$ [19]. Cell monolayers were infected at a multiplicity of infection (MOI) of 1 to 5 plaque-forming units (PFUs) per cell. Cells were incubated with viral inoculum for $60 \mathrm{~min}$ (MA104 cells) or $90 \mathrm{~min}$ (H69 cells) at $37^{\circ} \mathrm{C}$. Viral inoculum was replaced with FBS-free Eagle Minimal Essential Medium (MEM) (Invitrogen) containing $0.05 \mu \mathrm{g}$ of trypsin/mL. RRV titers were determined by plaque assay on MA104 cells [26].

2.2. Indirect Immunofluorescence (IF) Assay. Cells were seeded onto coverslips at a density of $5 \times 10^{4}$ cells/well in 6-well plates, infected with RRV or mock-infected, fixed with $4 \%$ paraformaldehyde, and permeabilized with $0.5 \%$ Triton-X100 in phosphate-buffered saline (PBS). The cells were subsequently incubated with guinea pig anti-RV VP6 polyclonal antisera (1:2000 dilution) and, in some cases, mouse anti-cytokeratins 7 and 19 monoclonal antibodies (1:1000 dilution). The cells were then incubated with rabbit anti-guinea pig Alexa Fluor 594 (1:1000; red signal) alone or with rabbit anti-mouse Alexa Fluor 488 (1:1000; green signal). Nuclei were stained with DAPI $\left(4^{\prime}, 6\right.$-diamidino-2phenylindole). Fluorescence was detected with an Olympus BX460 fluorescence microscope (Olympus, Center Valley, PA).

2.3. RNA Isolation and cDNA Synthesis. Total RNA was isolated from $1 \times 10^{8} \mathrm{H} 69$ cells using a NucleoSpin RNA L kit (Clontech, Mountain View, CA) according to the protocol of the manufacturer. Briefly, H69 cells were detached from culture flasks by incubation with $0.05 \%$ trypsin-EDTA, pelleted by low-speed centrifugation, and resuspended in lysis buffer. After homogenization, insoluble debris was removed by centrifugation through filter L columns. After addition of $70 \%$ ethanol, RNA was recovered from samples by binding to RNA L columns. 
TABLE 1: Primers used for qRT-PCR.

\begin{tabular}{lc}
\hline Primer & \multicolumn{1}{c}{ Sequence } \\
\hline GAPDH, forward & ACAGTCAGCCGCATCTTCTT \\
GAPDH, reverse & ACGACCAAATCCGTTGACTC \\
IL-6, forward & TGGAGATGTCTGAGGCTCATT \\
IL-6, reverse & CGCTTGTGGAGAAGGAGTTC \\
IL-8, forward & AGCTCTGTGTGAAGGTGCAG \\
IL-8, reverse & CAGAGCTCTCTTCCATCAGAAA \\
MCP-1, forward & AGCAAGTGTCCCAAAGAAGC \\
MCP-1, reverse & TGGAATCCTGAACCCACTTC \\
TGF $\beta 1$, forward & TTTTGATGTCACCGGAGTTG \\
TGF $\beta 1$, reverse & GAACCCGTTGATGTCCACTT \\
\hline
\end{tabular}

First-strand cDNA was synthesized from RNA using a Superscript III Reverse Transcriptase kit (Invitrogen). Polymerase chain reaction (PCR) amplification was performed using Platinum Taq DNA polymerase (Invitrogen) in reaction mixtures containing primers (Table 1 ) specific for human IL6, IL-8, MCP-1, TGF $\beta 1$, and GAPDH genes. After 2 min of an initial denaturation at $94^{\circ} \mathrm{C}, \mathrm{cDNAs}$ were amplified under the following conditions: 30 seconds ( $\mathrm{sec}$ ) at $94^{\circ} \mathrm{C}, 30 \mathrm{sec}$ at $56^{\circ} \mathrm{C}$, and $1 \mathrm{~min}$ at $72^{\circ} \mathrm{C}$ for a total of 35 cycles (Programmable Thermal Controller PTC-100, MJ Research Inc., Watertown, MA). PCR products were resolved by electrophoresis on $1.5 \%$ agarose gels and detected by staining with ethidium bromide and exposing to ultraviolet light.

2.4. Quantitative Real Time PCR ( $q R T-P C R)$. qRT-PCR was performed using JumpStart Taq Ready Mix (Sigma) and the ABI 7900 HT Fast Real Time PCR system (Applied Biosystem). qRT-PCR cycles included $2 \mathrm{~min}$ of initial denaturation at $94^{\circ} \mathrm{C}$, followed by 40 cycles of denaturation at $94^{\circ} \mathrm{C}$ for $15 \mathrm{sec}$ and annealing and extension at $60^{\circ} \mathrm{C}$ for $1 \mathrm{~min}$. qRTPCR results were analyzed by the Stratagene Mx4000 Quantitative PCR system. Values were normalized to those obtained for the housekeeping gene, GAPDH (glyceraldehyde-3phosphate dehydrogenase). For each specific gene, the mRNA relative expression in treated cells was reported as fold difference from or percent (\%) of untreated cells.

2.5. Human Cytokine-Expression Profile Analysis. Simultaneous detection of 23 human cytokines was performed in culture supernatants from RRV- or mock-infected H69 cells, using the human cytokine antibody array kit (C Series, AAHCYT-1 kit; Ray Biotech, Norcross, GA; the array map is shown in Table 2). The antibody array membranes were blocked and incubated with $1 \mathrm{~mL}$ of undiluted culture supernatant for $2 \mathrm{~h}$. After washing, a cocktail of biotin-conjugated anti-cytokine antibodies was added for $2 \mathrm{~h}$, followed by $1 \mathrm{~h}$ incubation with horseradish peroxidase-labeled streptavidin. After final washes, chemiluminescence images were captured and digitized using a laser-based scanner with charge coupled device camera system (Fujifilm LAS-3000, R\&D Systems Inc., Minneapolis, MN). Expression levels of cytokines were measured using Fujifilm Multi Gauge software (R\&D Systems).
2.6. Analysis of IL-6 and IL-8 Levels by Enzyme-Linked Immunosorbent Assay (ELISA). IL-6, IL-8, and IL-10 levels in the media of mock- or RRV-infected $\mathrm{H} 69$ cells at 24 and $48 \mathrm{~h}$ p.i. were quantified with Pierce human IL-6, IL-8, or IL-10 colorimetric ELISA kits (Thermo Fisher Scientific, Rockford, IL). The detection range is between 10 and $1000 \mathrm{pg} / \mathrm{mL}$. Samples above the maximum were diluted $1: 2$ in the reagent diluent provided with the kit and retested.

2.7. Mitogen-Activated Protein Kinase (MAPK) Pathway Inhibition. To study the effect of inhibition of MAPK pathways on RRV-induced IL-6 and IL-8 secretion, H69 cells were treated with the following MAPK inhibitors: an ERK1/2 inhibitor (U0126, Cell Signaling Technology, Inc., Danvers, MA), a p-38 inhibitor (SB203580, Invitrogen), and a JNK inhibitor (SP600125, EMD Biosciences, La Jolla, CA). All three inhibitors were prepared by dissolving in dimethyl sulfoxide (DMSO) at a concentration of $10 \mathrm{mM}$ and diluted 1000fold with culture medium. The final concentration of DMSO was $0.1 \%$ in all experiments. Cell monolayers were initially incubated for $2 \mathrm{~h}$ in L-15 medium containing $10 \mu \mathrm{M}$ of an inhibitor. Afterwards, the media were removed and the cells were washed with L-15 medium. The cells were then infected with RRV (MOI = 5) or mock-infected for $90 \mathrm{~min}$. The cells were washed 3 times with PBS, and postinfection medium with or without inhibitors $(10 \mu \mathrm{M})$ was placed on the cells. Levels of IL- 6 and IL-8 in cell culture media recovered from mock- or RRV-infected H69 cells at 24 and $48 \mathrm{~h}$ p.i. were quantified using Pierce ELISA kits.

2.8. Statistics. Experiments were performed in duplicate (immunofluorescence and human cytokine antibody array) and triplicate (ELISA, qRT-PCR, and MAPK inhibition) and were repeated 2 or more times (mock and RRV infection of $\mathrm{H} 69$ cells). One-tailed Student's $t$-test was performed to compare the means of two populations. In the bar graphs, data represent the mean \pm standard deviation (SD) of multiple repeats. $\chi^{2}$ test was performed to compare the values of two populations. A $p$ value of less than 0.05 was considered significant. The ${ }^{*} p<0.01$ was used to indicate statistical significance of differences between samples.

\section{Results}

3.1. Human Biliary Epithelial Cells Are Susceptible to Infection by $R R V$. Infection of MA104 cells at an MOI of 1 with RRV resulted in extensive cytopathic effects (CPE) and the loss of the cell monolayer by $15 \mathrm{~h}$ p.i. In contrast, no cytolysis was obvious in RRV-infected $\mathrm{H} 69$ cells at $24 \mathrm{~h}$ p.i. at an MOI of either 1 or 5 . Moreover, trypan-blue exclusion analysis showed no difference in the viability of mock- and RRVinfected cells at either 24 or $48 \mathrm{~h}$ p.i. However, IF assays with RV VP6 antibody revealed the presence of viroplasms in the cytoplasm of infected but not mock-infected H69 cells (Figures 1(a) and 1(b)). Specifically, 25\% of RRV-infected H69 cells infected at an MOI of 5 contained viroplasms. IF assays also showed that the infected $\mathrm{H} 69$ cells expressed cytokeratins 7 (Figures 1(c)-1(e)) and 19 (data not shown), confirming their bile duct epithelial histotype (Figures 1(c)-1(e)). 
TABLe 2: Array map.

\begin{tabular}{ccccccccc}
\hline & A & B & C & D & E & F & G \\
\hline 1 & POS & POS & NEG & NEG & G-CFS & GM-CFS & GRO & GRO- $\alpha$ \\
2 & POS & POS & NEG & NEG & G-CFS & GM-CFS & GRO & GRO- $\alpha$ \\
3 & IL-1 $\alpha$ & IL-2 & IL-3 & IL-5 & IL-6 & IL-7 & IL-8 & IL-10 \\
4 & IL-1 $\alpha$ & IL-2 & IL-3 & IL-5 & IL-6 & IL-7 & IL-8 & IL-10 \\
5 & IL-13 & IL-15 & IFN $\gamma$ & MCP-1 & MCP-2 & MCP-3 & MIG & RANTES \\
6 & IL-13 & IL-15 & IFN $\gamma$ & MCP-1 & MCP-2 & MCP-3 & MIG & RANTES \\
7 & TGF $\beta 1$ & TNF $\alpha$ & TNF $\beta$ & BLANK & BLANK & BLANK & BLANK & POS \\
8 & TGF $\beta 1$ & TNF $\alpha$ & TNF $\beta$ & BLANK & BLANK & BLANK & BLANK & POS \\
\hline
\end{tabular}

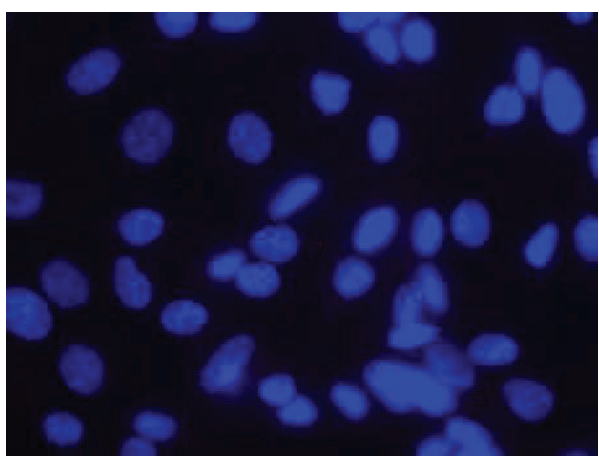

(a)

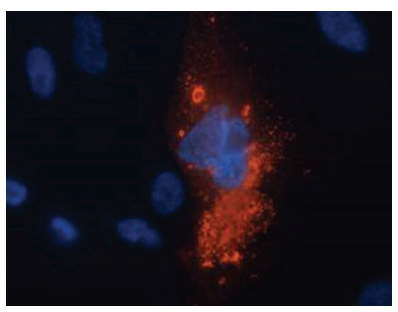

(c)

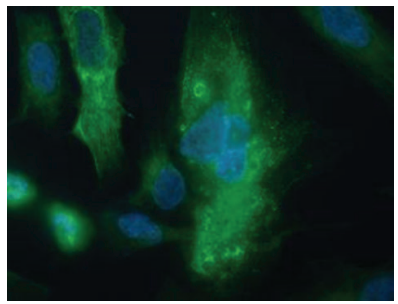

(d)

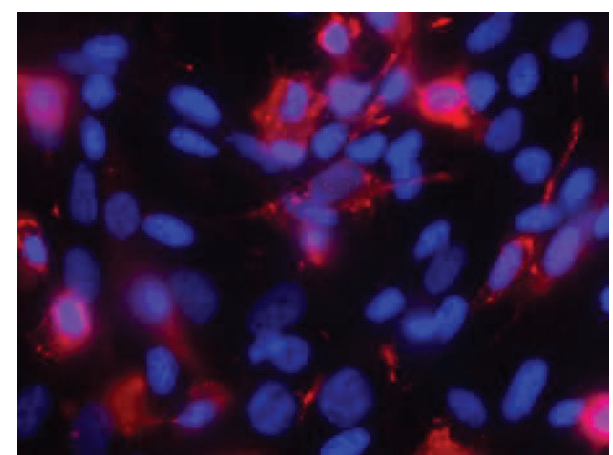

(b)

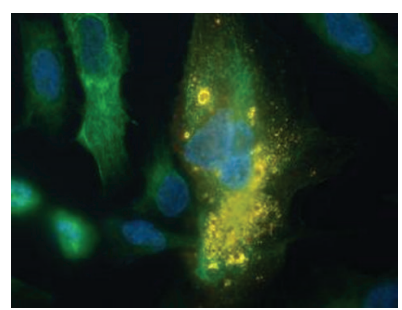

(e)

FIGURE 1: Top panels: immunofluorescence staining of mock- (a) and RRV- (b) infected H69 cells (MOI of 5, 24h p.i.) using anti-RV VP6 antibody; red cytoplasm fluorescence indicates RRV-infected cells (magnification 40x). Bottom panels: double immunofluorescence staining with anti-RV VP6 (red, c) and CK-7 (green, d) antibodies of RRV-infected H69 cells; (e) is a merged image of (c) and (d). Blue counterstaining of nuclei by DAPI.

To test whether $\mathrm{H} 69$ cells supported productive replication of RRV, supernatants recovered at 2, 24, and $48 \mathrm{~h}$ p.i. from RRV-infected and mock-infected H69 cells were analyzed by plaque assay on MA104 cells. The results showed a progressive increase in RRV titers, beginning with $10^{2} \mathrm{PFU} / \mathrm{mL}$ at $2 \mathrm{~h}$ p.i., reaching $10^{6} \mathrm{PFU} / \mathrm{mL}$ at $24 \mathrm{~h}$ p.i. and $10^{8} \mathrm{PFU} / \mathrm{mL}$ at $48 \mathrm{~h}$ p.i., Thus, the $\mathrm{H} 69$ cells represent a permissive cell line for RRV growth. This conclusion was further supported by transfer of "postinfection" medium from RRV-infected H69 cells onto MA104 cell monolayers, which resulted in the complete cytolysis of the monolayers upon overnight incubation. As expected, transfer of "postinfection" medium from mock-infected H69 cells to MA104 cells did not result in cytolysis.

3.2. RRV-Infected Human Biliary Epithelial Cells and IL-6 and IL-8 Cytokines. The presence of cytokines in the media of mock-infected and RRV-infected H69 cells at 24 and $48 \mathrm{~h}$ p.i. $(\mathrm{MOI}=1)$ was screened using a cytokine antibody array assay (Figure 2). The analysis showed that detectable levels of GRO, GRO- $\alpha$, RANTES, and IL- 8 were present in the media of mock-infected $\mathrm{H} 69$ cells at $24 \mathrm{~h}$ p.i. RRV infection resulted in higher levels of IL-6 and IL-8 accumulation in the media and slightly higher levels of IL-7, IL-10, GRO, and GRO- $\alpha$ at $24 \mathrm{~h}$ p.i. as compared to mock infection (Figure 2). Likewise, the levels of these cytokines, as well as RANTES, were higher at $48 \mathrm{~h}$ p.i. than at $24 \mathrm{~h}$ p.i. in RRV-infected-cell media. These results indicate that RRV infection stimulates the expression of some cytokines by H69 cells, notably IL-6, IL-8, and IL-10, which appears to increase overtime.

To validate and quantify the results obtained with the cytokine antibody array assay, the concentrations of IL-6, IL8 , and IL-10 in the media of mock-infected and RRV-infected H69 cells (MOI $=1$ ) were determined by ELISA. As above, the results showed that little or no IL-6 was present in uninfectedcell media at $24 \mathrm{~h}$ p.i., with only low levels detectable in 


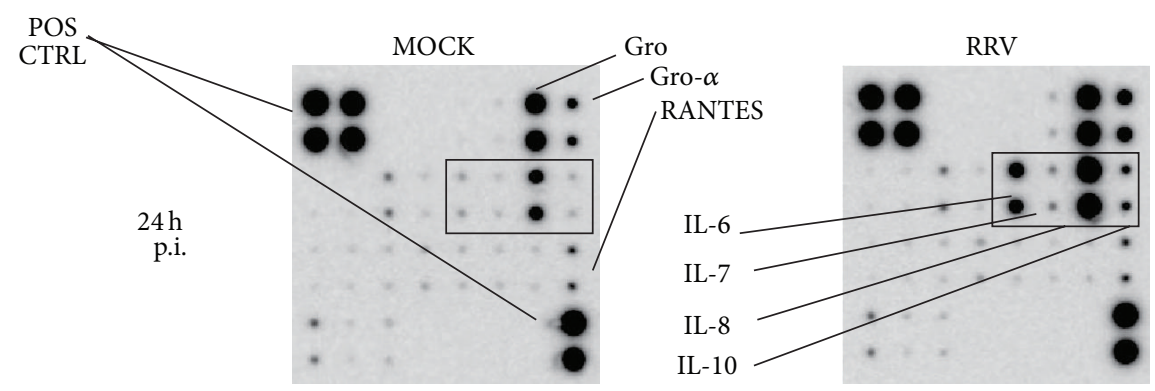

(a)

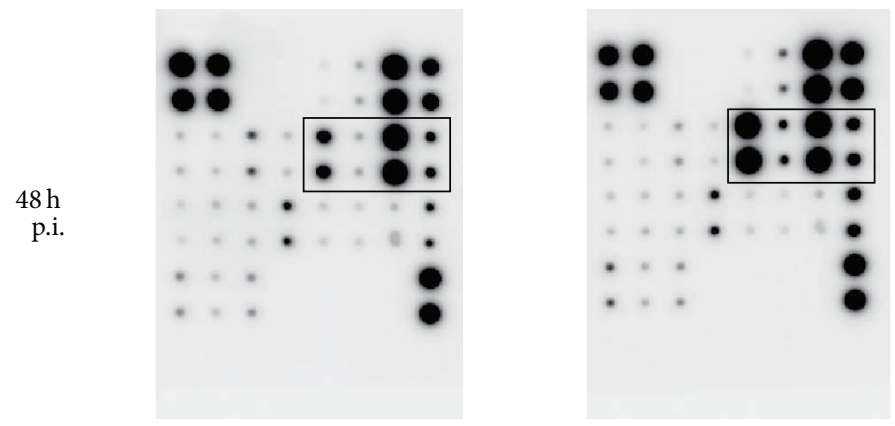

(b)

FIGURE 2: Results of the cytokine array antibody membrane assay: cytokines present in media of mock- and RRV-infected H69 cells at 24 (a) and $48 \mathrm{~h}$ p.i. (b). The rectangle in all four membranes indicates IL-6, IL-7, IL-8, and IL-10, the locations of which are indicated in the upper right membrane.

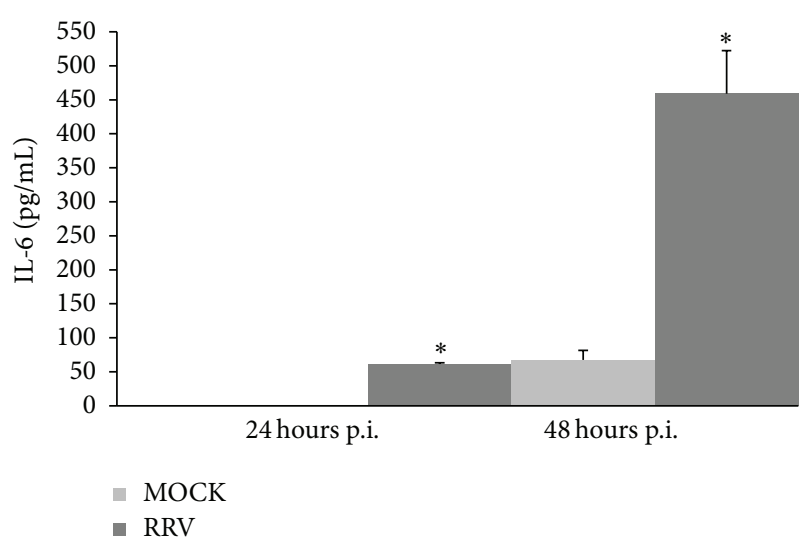

(a)

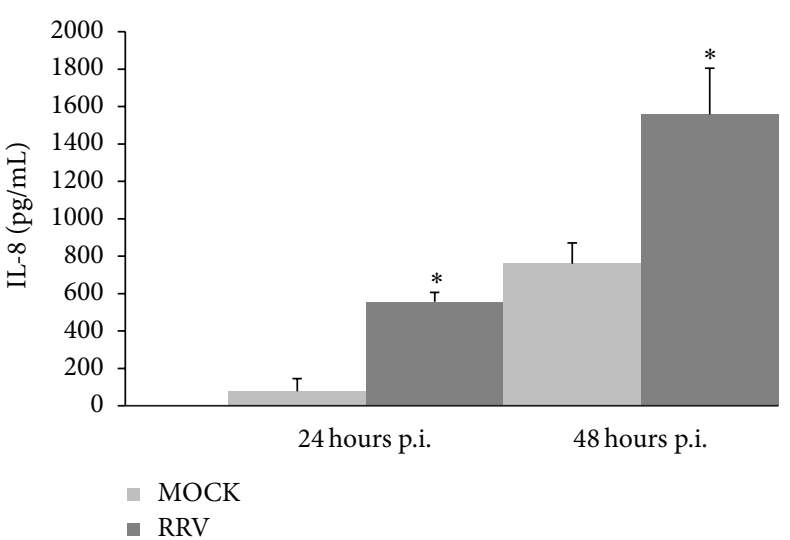

(b)

FIGURE 3: IL-6 (a) and IL-8 (b) detection by ELISA in media of mock- and RRV-infected cells at 24 and 48 h p.i. Bar graphs indicate the mean \pm standard deviation (SD) of multiple repeats. Asterisks indicate significant difference between mock and RRV at each time point. ${ }^{*} p$ value $<0.01$ from mock-infected cells.

the media of such cells at $48 \mathrm{~h}$ p.i. $(67.4 \pm 13.9 \mathrm{pg} / \mathrm{mL})$ (Figure 3(a)). In contrast, infected-cell media contained readily measurable IL-6 levels at $24 \mathrm{~h}$ p.i. $(61.2 \pm 1.9 \mathrm{pg} / \mathrm{mL})$ ( $p<0.0001$ for infected versus mock-infected) and even greater levels at $48 \mathrm{~h}$ p.i. $(458.8 \pm 63.5 \mathrm{pg} / \mathrm{mL})(p<0.00020$ for infected versus mock-infected). Not unexpectedly, IL-6 levels in the media were dependent on infection conditions, with IL- 6 concentrations 3.6-fold higher at an MOI of 5 than at an MOI of 1 in RRV-infected cells at $24 \mathrm{~h}$ p.i. $(p<0.001$; Figure 4(a)) but not in mock-infected cells (Figure 4(a)). At
$24 \mathrm{~h}$ p.i., IL-6 level was $76 \pm 3.1 \mathrm{pg} / \mathrm{mL}$ at $\mathrm{MOI}=1$ versus $273 \pm 22.8 \mathrm{pg} / \mathrm{mL}$ at MOI $=5$ in RRV-infected cells, while IL- 6 was undetectable in mock-infected cells at both $\mathrm{MOI}=1$ and MOI $=5$ (Figure 4(a)).

ELISA analysis revealed that, at $24 \mathrm{~h}$ p.i., IL- 8 levels in the media of RRV-infected $\mathrm{H} 69$ cells $(556.5 \pm 111 \mathrm{pg} / \mathrm{mL})$ were $\sim 7$-fold higher than in the media of mock-infected cells $(77.0 \pm 68 \mathrm{pg} / \mathrm{mL})(p<0.0042$ for RRV-infected versus mockinfected) (Figure 3(b)). At $48 \mathrm{~h}$ p.i., levels of IL-8 in infectedcell media $(1558.6 \pm 246 \mathrm{pg} / \mathrm{mL})$ were approximately twice as 


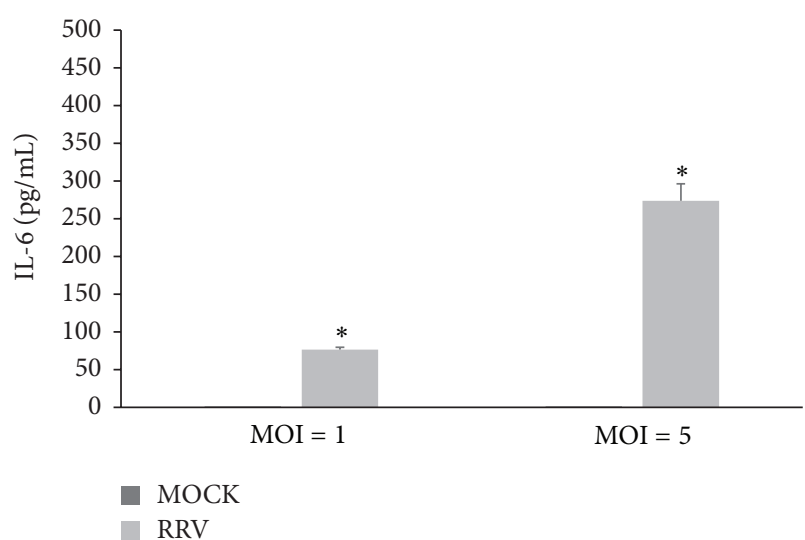

(a)

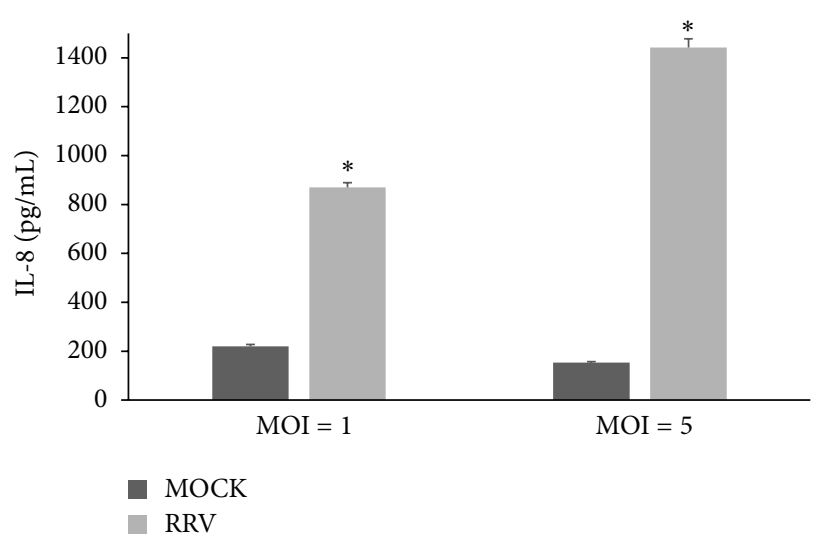

(b)

FIGURE 4: IL-6 (a) and IL-8 (b) detection (pg/mL) by ELISA in media of mock- and RRV-infected H69 cells at $24 \mathrm{~h}$ p.i. $(\mathrm{MOI}=1 \mathrm{and}$ MOI = $5)$. Bar graphs indicate the mean \pm standard deviation (SD) of multiple repeats. Asterisks indicate significant difference between mock and RRV at each MOI. ${ }^{*} p$ value $<0.01$ from mock-infected cells.

high as that of uninfected-cell media $(760.0 \pm 49.9 \mathrm{pg} / \mathrm{mL})$ ( $p=0.011$ for RRV-infected versus mock-infected). IL-8 media levels were also influenced by MOI, with levels 1.6-fold higher in the media of $\mathrm{H} 69$ cells infected with RRV at an MOI of 5 than 1 ( $p<0.001$; Figure 4(b)). At 24 h p.i., IL-8 level was $870 \pm 19.3 \mathrm{pg} / \mathrm{mL}$ at $\mathrm{MOI}=1$ versus $1442 \pm 36 \mathrm{pg} / \mathrm{mL}$ at $\mathrm{MOI}=$ 5 in RRV-infected cells, while IL- 8 was $220 \pm 7.3 \mathrm{pg} / \mathrm{mL}$ at $\mathrm{MOI}=1$ versus $153 \pm 4.6 \mathrm{pg} / \mathrm{mL}$ at $\mathrm{MOI}=5$ in mock-infected cells (Figure 4(b)). IL-10 was not detectable by ELISA in the media of mock- or RRV-infected cells at either 24 or $48 \mathrm{~h}$ p.i. (data not shown).

To further evaluate the effect of RRV infection on the expression of cytokines in H69 cells, levels of IL- 6 and IL8 mRNAs in mock and infected cells recovered at $24 \mathrm{~h}$ p.i. were determined by qRT-PCR. As shown in Figure 5, IL-6 and IL-8 mRNA levels were approximately 6 -fold and 1.5 -fold higher, respectively, in infected $\mathrm{H} 69$ cells than in uninfected cells. These results are consistent with those presented above (Figures 2-4) which indicates that RRV infection stimulates the expression of IL- 6 and IL-8 cytokines by H69 cells. In contrast, qRT-PCR analysis revealed that RRV infection had no impact on the mRNA levels of two other cytokines, MCP1 and TGF $\beta 1$, used as negative controls in these experiments (data not shown).

3.3. Effect of MAPK Inhibitors on IL-6 and IL-8 in RRVInfected $H 69$ Cells. The importance of MAPK activation in the release of IL- 6 and IL-8 from RRV-infected H69 cells was examined using the MAPK inhibitors to ERK 2/1, p-38, and JNK. No difference in the viability of mock- and RRVinfected cells treated with the MAPK inhibitors (which were dissolved in $0.1 \%$ DMSO) was found by trypan-blue exclusion at either 24 or 48 h p.i. Treatment of RRV-infected H69 cells with SB203580 (p-38 inhibitor) had the greatest effect on IL6 and IL- 8 accumulation in media, as assessed by ELISA, reducing their levels by $\sim 90 \%$ (Figure $6(\mathrm{a})$ ). In contrast, U0126 and SP600125 (ERK 1/2 and JNK inhibitors, resp.) treatment reduced IL- 6 and IL-8 levels by roughly one-half.

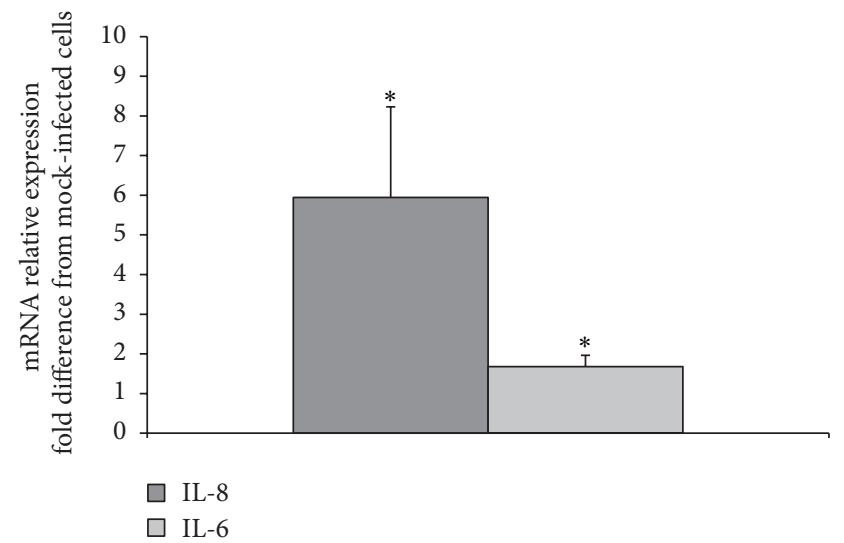

FIGURE 5: qRT-PCR results: relative expression of IL-6 and IL-8 mRNAs at $24 \mathrm{~h}$ p.i. in RRV-infected H69 cells expressed as fold difference from mock. ${ }^{*} p$ value $<0.01$.

The effect of the MAPK inhibitors on IL- 6 and IL-8 mRNA expression was analyzed by qRT-PCR. As shown in Figure 6(b), treatment of RRV-infected cells with SB203580 decreased mRNA expression of both IL-8 (11\% of values observed in RRV-infected cells not treated with inhibitor) and IL-6 (28\%). When RRV-infected cells were treated with U0126, mRNA expression of IL-8 was $34 \%$ of values observed in RRV-infected cells not treated with inhibitor. RNA expression of IL-8 mRNA was not affected when RRVinfected cells were treated with SP600125; mRNA expression of IL- 6 was $70 \%$ of values observed in RRV-infected cells not treated with SP600125.

Results of the plaque assay experiments showed that the treatment with any of the three MAPK inhibitors did not affect the replication of RRV, as this treatment did not affect the titer of RRV in infected $\mathrm{H} 69$ cells. 


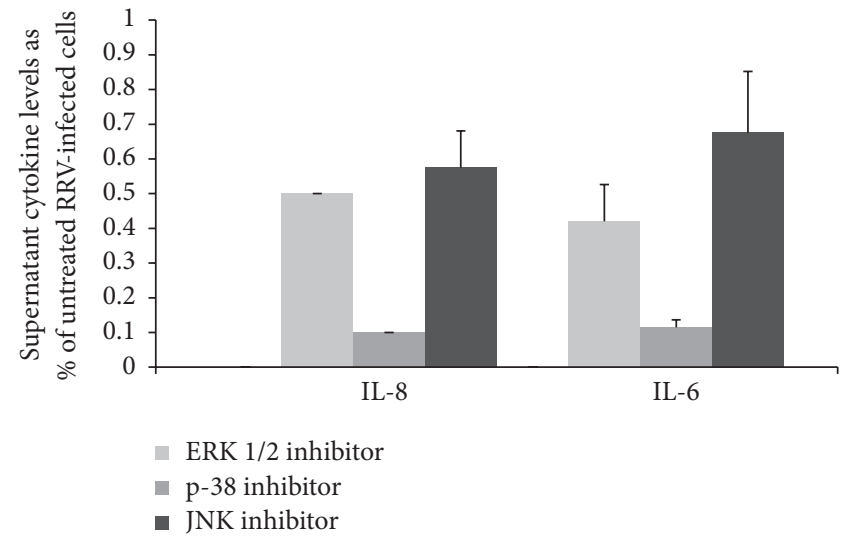

(a)

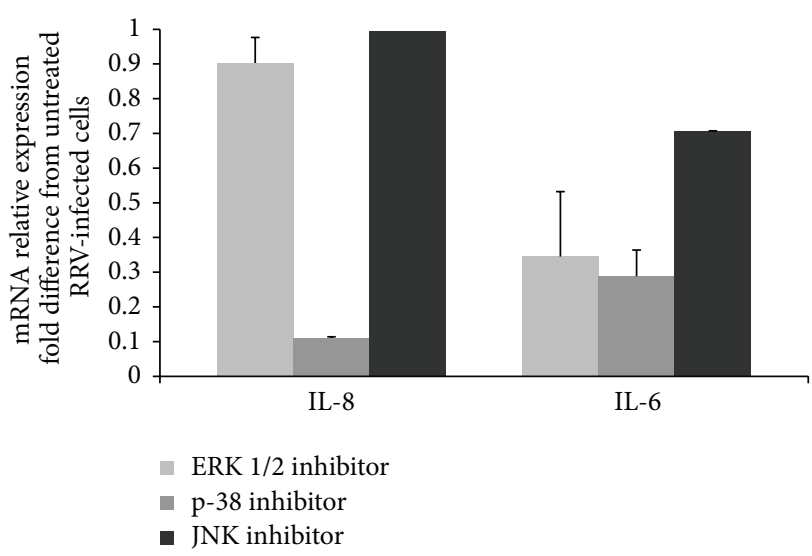

(b)

FIGURE 6: (a) IL-6 and IL-8 levels, measured by ELISA, in the media of RRV-infected H69 cells treated with MAPK inhibitors (p-38, ERK 1/2, and JNK inhibitors), expressed as \% of untreated RRV-infected cells. (b) IL-6 and IL-8 mRNA levels, measured by qRT-PCR, in RRV-infected H69 cells treated with MAPK inhibitors (p-38, ERK 1/2, and JNK inhibitors), expressed as fold difference from untreated RRV-infected H69 cells. Bar graphs indicate the mean \pm standard deviation (SD) of multiple repeats.

\section{Discussion}

This study confirms that human biliary epithelial cells are susceptible to productive infection with RRV. RRV infection of human biliary epithelial cells in vitro was associated with the increased release of proinflammatory and profibrotic cytokines, such as IL-6 and IL-8, into the media of infected cells. Inhibition of MAPK cell signaling pathway resulted in decreased amounts of both cytokines in the media.

Unlike infection of MA104 cells with RRV, RRV infection of human biliary epithelial cells was not cytolytic but resulted in the release of infectious virions into the cell culture medium, from which infection could be transmitted to MA104 cells with resultant cytolysis. Furthermore, RRV infection of human biliary epithelial cells resulted in a timedependent increase in the supernatant levels of two proinflammatory and profibrotic cytokines, IL- 8 and IL-6. Treatment of the infected cells with a MAPK p-38 inhibitor was associated with a marked reduction in the amount of IL- 6 and IL-8 detectable in the supernatant.

The mitogen-activated protein kinase (MAPK) pathway is one of the intracellular signaling pathways that are activated in response to RV infection in different epithelial cell lines, including mouse cholangiocytes [22]. Following RV infection, activation of the MAPK cascade leads to the upregulation of cellular genes. In a human intestinal epithelial cell line (Caco2), RV infection has been reported to be associated with a significant increase in the expression of IL-8 through MAPK p-38 [27]. The promoter of the IL- 8 gene has been found to have a binding site for AP-1, which is the last protein to be activated in the MAPK p-38 intracellular cascade [27].

Human cholangiocytes are known to release both IL-6 and IL-8 in response to a variety of injuries in vivo $[28,29]$. Release of IL-6 occurs when human cholangiocytes are exposed to bacterial lipopolysaccharide [30]. MAPK activity increases in a time- and dose-dependent way in RV-infected mouse cholangiocytes both in vitro and in vivo, where it is associated with increased production of inflammatory chemokines [22, 23].

Interestingly, as noted above, these two proinflammatory and profibrotic cytokines are thought to be major mediators of tissue damage in acquired BA. Moreover, analysis of BA livers by microarray and qRT-PCR demonstrated prominent expression of proinflammatory genes at early stages of acquired BA, where IL- 8 was by far the most upregulated gene (a 17-fold increased expression compared to livers of infants with other cholestatic disorders) [31]. Elevated serum IL- 8 has been detected in BA infants with jaundice and/or portal hypertension $[32,33]$, and the serum concentration of IL- 6 has been found to correlate with the severity of BA [34]. IL-6 is released from biliary epithelial cells during liver injury where it directly promotes cell proliferation allowing cell survival and regeneration [35]. Thus IL-6 secretion might represent a means of defense for human biliary epithelial cells to control and to survive the viral infection, explaining why RRV infection did not result in $\mathrm{H} 69$ cell lysis in vitro [35]. It is interesting to note that the RRV-infected media which resulted in cytolysis in MA104 cells contained both RRV and cytokines. Either IL-6 or possibly other cytokines might have differential effects on cell survival in MA104 and H69 cells or the differential survival of the two cell types in response to RRV infection may be explained by factors other than cytokines.

We should note that our results do not imply a causal role for RV alone in BA especially given our recent observation that the prevalence of $\mathrm{RV}$ infection in $\mathrm{BA}$ versus other cholestasis disorders (10-40\% in BA versus $18-37 \%$ in other cholestatic infants) was almost identical [21]. If RV (or any other virus) plays any role in BA, genetically determined differences in immune response to viral infections are likely involved, including differential cytokine responses. As we noted [21] there is substantial precedent for differential host immune responses to infections with other viruses such as hepatitis $\mathrm{C}$ virus and HIV. 
Our observations that RRV infection of human cholangiocytes involves MAP kinase activation suggests another intriguing avenue by which viral infection might be implicated in the pathogenesis of BA, as prolonged activation of this kinase induced by a viral infection early in life might lead to unbalanced expression of cytokines such as IL-6 and IL-8, which have been associated with progression toward a severe BA phenotype.

In the well-known experimental murine model of RRVinduced BA-like disease, where the hepatobiliary disease progresses in the absence of detectable virus, the potential therapeutic use of MAPK blockers could be explored.

$\begin{array}{ll}\text { Abbreviations } \\ \text { BA: } & \text { Biliary atresia } \\ \text { cDNA: } & \text { Complementary deoxyribonucleic acid } \\ \text { DAPI: } & 4^{\prime} \text {,6-Diamidino-2-phenylindole } \\ \text { ELISA: } & \text { Enzyme-linked immunosorbent assay } \\ \text { FBS: } & \text { Fetal bovine serum } \\ \text { GAPDH: } & \text { Glyceraldehyde-3-phosphate dehydrogenase } \\ \text { h p.i.: } & \text { Hours postinfection } \\ \text { IF: } & \text { Indirect immunofluorescence } \\ \text { IL-6: } & \text { Interleukin-6 } \\ \text { IL-8: } & \text { Interleukin-8 } \\ \text { MAPK: } & \text { Mitogen-activated protein kinase } \\ \text { MEM: } & \text { Minimal Essential Medium } \\ \text { min: } & \text { Minutes } \\ \text { MOI: } & \text { Multiplicity of infection } \\ \text { mRNA: } & \text { Messenger RNA } \\ \text { PBS: } & \text { Phosphate-buffered saline } \\ \text { PCR: } & \text { Polymerase chain reaction } \\ \text { pfu: } & \text { Plaque-forming unit } \\ \text { qRT-PCR: } & \text { Quantitative real time polymerase chain } \\ & \text { reaction } \\ \text { RNA: } & \text { Ribonucleic acid } \\ \text { RRV: } & \text { Rhesus rotavirus } \\ \text { RV: } & \text { Rotavirus } \\ \text { sec: } & \text { Seconds. }\end{array}$

\section{Conflict of Interests}

The authors declare that there is no conflict of interests regarding the publication of this paper.

\section{Acknowledgments}

This work is supported in part by the Zachary Meehan Biliary Atresia Foundation, Sydney Moss Bilary Atresia Foundation, and the Johns Hopkins Pediatric Liver Center (M. G. Clemente) and the Intramural Research Program of the National Institute of Allergy and Infectious Diseases, National Institutes of Health (J. Patton).

\section{References}

[1] K. B. Schwarz, B. H. Haber, P. Rosenthal et al., "Extrahepatic anomalies in infants with biliary atresia: results of a large prospective North American multicenter study," Hepatology, vol. 58, no. 5, pp. 1724-1731, 2013.

[2] M.-M. Garcia-Barceló, M.-Y. Yeung, X.-P. Miao et al., "Genomewide association study identifies a susceptibility locus for biliary atresia on 10q24.2," Human Molecular Genetics, vol. 19, no. 14, pp. 2917-2925, 2010.

[3] J. L. Hartley, M. Davenport, and D. A. Kelly, "Biliary atresia," The Lancet, vol. 374, no. 9702, pp. 1704-1713, 2009.

[4] C. L. Mack and R. J. Sokol, "Unraveling the pathogenesis and etiology of biliary atresia," Pediatric Research, vol. 57, no. 5, pp. 87R-94R, 2005.

[5] P. Chomarat, J. Banchereau, J. Davoust, and A. K. Palucka, "IL6 switches the differentiation of monocytes from dendritic cells to macrophages," Nature Immunology, vol. 1, no. 6, pp. 510-514, 2000.

[6] M. E. W. Hammond, G. R. Lapointe, P. H. Feucht et al., "IL-8 induces neutrophil chemotaxis predominantly via type I IL-8 receptors," The Journal of Immunology, vol. 155, no. 3, pp. 14281433, 1995.

[7] M. Davenport, C. Gonde, R. Redkar et al., "Immunohistochemistry of the liver and biliary tree in extrahepatic biliary atresia," Journal of Pediatric Surgery, vol. 36, no. 7, pp. 1017-1025, 2001.

[8] S. Changho and A. A. Ahmed, "Neutrophils in biliary atresia. A study on their morphologic distribution and expression of CAP37," Pathology Research and Practice, vol. 206, no. 5, pp. 314317, 2010.

[9] Y.-H. Huang, M.-H. Chou, Y.-Y. Du et al., "Expression of tolllike receptors and type 1 interferon specific protein MxA in biliary atresia," Laboratory Investigation, vol. 87, no. 1, pp. 6674, 2007.

[10] S. Rauschenfels, M. Krassmann, A. N. Al-Masri et al., "Incidence of hepatotropic viruses in biliary atresia," European Journal of Pediatrics, vol. 168, no. 4, pp. 469-476, 2009.

[11] C. L. Mack, R. M. Tucker, B. R. Lu et al., "Cellular and humoral autoimmunity directed at bile duct epithelia in murine biliary atresia," Hepatology, vol. 44, no. 5, pp. 1231-1239, 2006.

[12] M. Riepenhoff-Talty, V. Gouvea, M. J. Evans et al., "Detection of group C rotavirus in infants with extrahepatic biliary atresia," Journal of Infectious Diseases, vol. 174, no. 1, pp. 8-15, 1996.

[13] K. B. Schwarz, T. J. Moore, R. E. Willoughby Jr., S.-B. Wee, S. L. Vonderfecht, and R. H. Yolken, "Growth of group a rotaviruses in a human liver cell line," Hepatology, vol. 12, no. 4, pp. 638-643, 1990.

[14] J. E. Tate, M. M. Patel, A. D. Steele et al., "Global impact of rotavirus vaccines," Expert Review of Vaccines, vol. 9, no. 4, pp. 395-407, 2010.

[15] S. E. Crawford, D. G. Patel, E. Cheng et al., "Rotavirus viremia and extraintestinal viral infection in the neonatal rat model," Journal of Virology, vol. 80, no. 10, pp. 4820-4832, 2006.

[16] M. Fenaux, M. A. Cuadras, N. Feng, M. Jaimes, and H. B. Greenberg, "Extraintestinal spread and replication of a homologous EC rotavirus strain and a heterologous rhesus rotavirus in BALB/c mice," Journal of Virology, vol. 80, no. 11, pp. 5219-5232, 2006.

[17] K. Sugata, K. Taniguchi, A. Yui et al., "Analysis of rotavirus antigenemia and extraintestinal manifestations in children with rotavirus gastroenteritis," Pediatrics, vol. 122, no. 2, pp. 392-397, 2008.

[18] M. A. Gilger, D. O. Matson, M. E. Conner, H. M. Rosenblatt, M. J. Finegold, and M. K. Estes, "Extraintestinal rotavirus infections in children with immunodeficiency," The Journal of Pediatrics, vol. 120, no. 6, pp. 912-917, 1992. 
[19] R. Zbinden, J. Kunz, U. B. Schaad, U. Schilt, and R. Slongo, "Incidence and diagnosis of rotavirus infection in neonates: results of two studies," Journal of Perinatal Medicine, vol. 18, no. 5, pp. 363-368, 1990.

[20] L. Bobo, C. Ojeh, D. Chiu, A. Machado, P. Colombani, and K. Schwarz, "Lack of evidence for rotavirus by polymerase chain reaction/enzyme immunoassay of hepatobiliary samples from children with biliary atresia," Pediatric Research, vol. 41, no. 2, pp. 229-234, 1997.

[21] M. G. Clemente, J. T. Patton, R. Yolken et al., "Prevalence of groups a and $\mathrm{C}$ rotavirus antibodies in infants with biliary atresia and cholestatic controls," Journal of Pediatrics, vol. 166, no. 1, pp. 79.el-84.e1, 2015.

[22] M. Jafri, B. Donnelly, M. McNeal, R. Ward, and G. Tiao, "MAPK signaling contributes to rotaviral-induced cholangiocyte injury and viral replication," Surgery, vol. 142, no. 2, pp. 192-201, 2007.

[23] M. Jafri, B. Donnelly, A. Bondoc, S. Allen, and G. Tiao, "Cholangiocyte secretion of chemokines in experimental biliary atresia," Journal of Pediatric Surgery, vol. 44, no. 3, pp. 500-507, 2009.

[24] A. Coots, B. Donnelly, S. K. Mohanty, M. McNeal, K. Sestak, and G. Tiao, "Rotavirus infection of human cholangiocytes parallels the murine model of biliary atresia," Journal of Surgical Research, vol. 177, no. 2, pp. 275-281, 2012.

[25] S. A. Grubman, R. D. Perrone, D. W. Lee et al., "Regulation of intracellular $\mathrm{pH}$ by immortalized human intrahepatic biliary epithelial cell lines," American Journal of Physiology, vol. 266, no. 6, pp. G1060-G1070, 1994.

[26] M. Arnold, J. T. Patton, and S. M. McDonald, "Culturing, storage, and quantification of rotaviruses," in Current Protocols in Microbiology, chapter 15, unit 15C.3, John Wiley \& Sons, 2009.

[27] G. Holloway and B. S. Coulson, "Rotavirus activates JNK and p38 signaling pathways in intestinal cells, leading to AP-1-driven transcriptional responses and enhanced virus replication," Journal of Virology, vol. 80, no. 21, pp. 10624-10633, 2006.

[28] T. Yokoyama, A. Komori, M. Nakamura et al., "Human intrahepatic biliary epithelial cells function in innate immunity by producing IL-6 and IL-8 via the TLR4-NF-kappaB and -MAPK signaling pathways," Liver International, vol. 26, no. 4, pp. 467476, 2006.

[29] X.-M. Chen, S. P. O'Hara, and N. F. LaRusso, "The immunobiology of cholangiocytes," Immunology and Cell Biology, vol. 86, no. 6, pp. 497-505, 2008.

[30] S. P. O’Hara, P. L. Splinter, C. E. Trussoni, G. B. Gajdos, P. N. Lineswala, and N. F. LaRusso, "Cholangiocyte N-Ras protein mediates lipopolysaccharide-induced interleukin 6 secretion and proliferation," The Journal of Biological Chemistry, vol. 286, no. 35, pp. 30352-30360, 2011.

[31] J. A. Bezerra, G. Tiao, F. C. Ryckman et al., "Genetic induction of proinflammatory immunity in children with biliary atresia," The Lancet, vol. 360, no. 9346, pp. 1653-1659, 2002.

[32] V. Nobili, M. Marcellini, L. Giovannelli et al., "Association of serum interleukin-8 levels with the degree of fibrosis in infants with chronic liver disease," Journal of Pediatric Gastroenterology and Nutrition, vol. 39, no. 5, pp. 540-544, 2004.

[33] K. Moyer, V. Kaimal, C. Pacheco et al., "Staging of biliary atresia at diagnosis by molecular profiling of the liver," Genome Medicine, vol. 2, article 33, 2010.

[34] H. Kobayashi, A. Yamataka, G. J. Lane, and T. Miyano, "Levels of circulating antiinflammatory cytokine interleukin-1 receptor antagonist and proinflammatory cytokines at different stages of biliary atresia," Journal of Pediatric Surgery, vol. 37, no. 7, pp. 1038-1041, 2002.
[35] J. Yu, N. Sheung, E. M. Soliman, C. Spirli, and J. A. Dranoff, "Transcriptional regulation of IL-6 in bile duct epithelia by extracellular ATP," The American Journal of PhysiologyGastrointestinal and Liver Physiology, vol. 296, no. 3, pp. G563G571, 2009. 


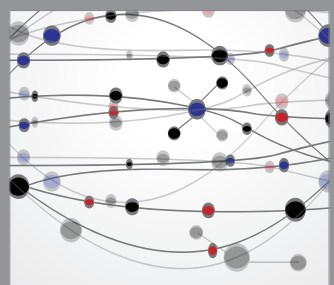

The Scientific World Journal
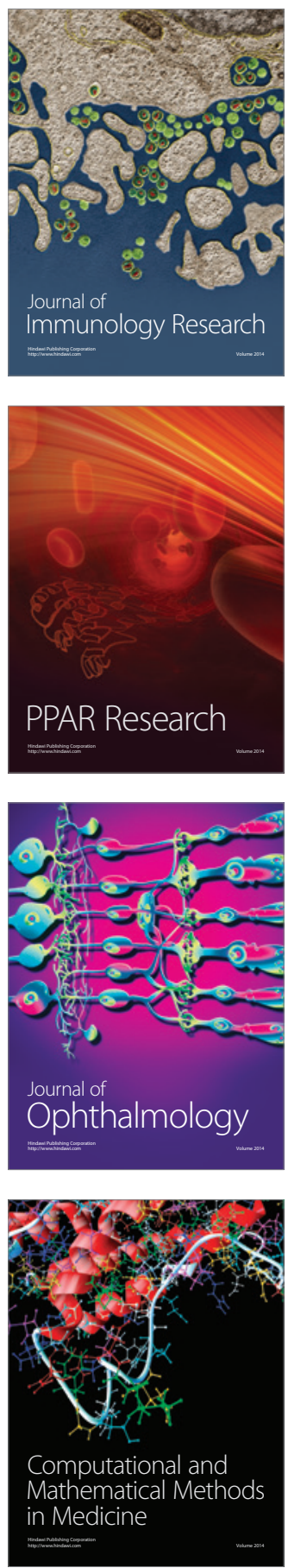

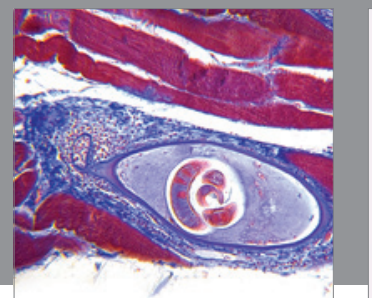

Gastroenterology

Research and Practice
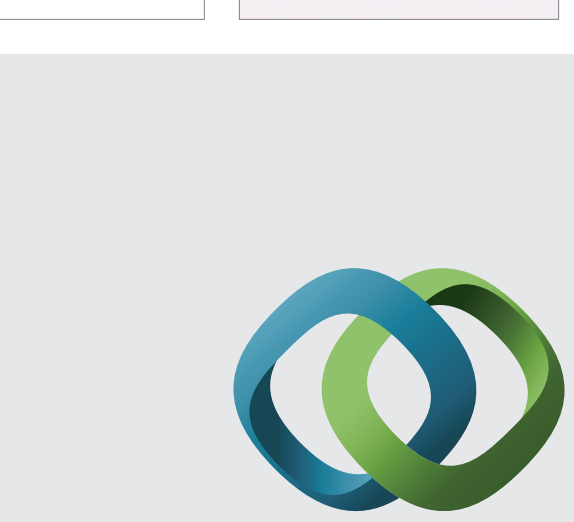

\section{Hindawi}

Submit your manuscripts at

http://www.hindawi.com
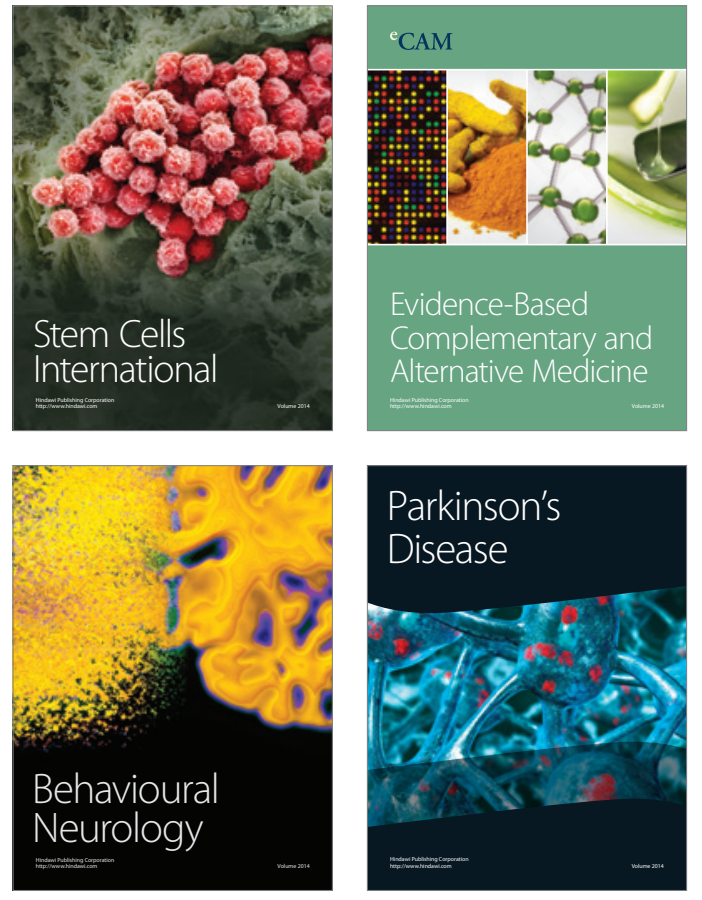
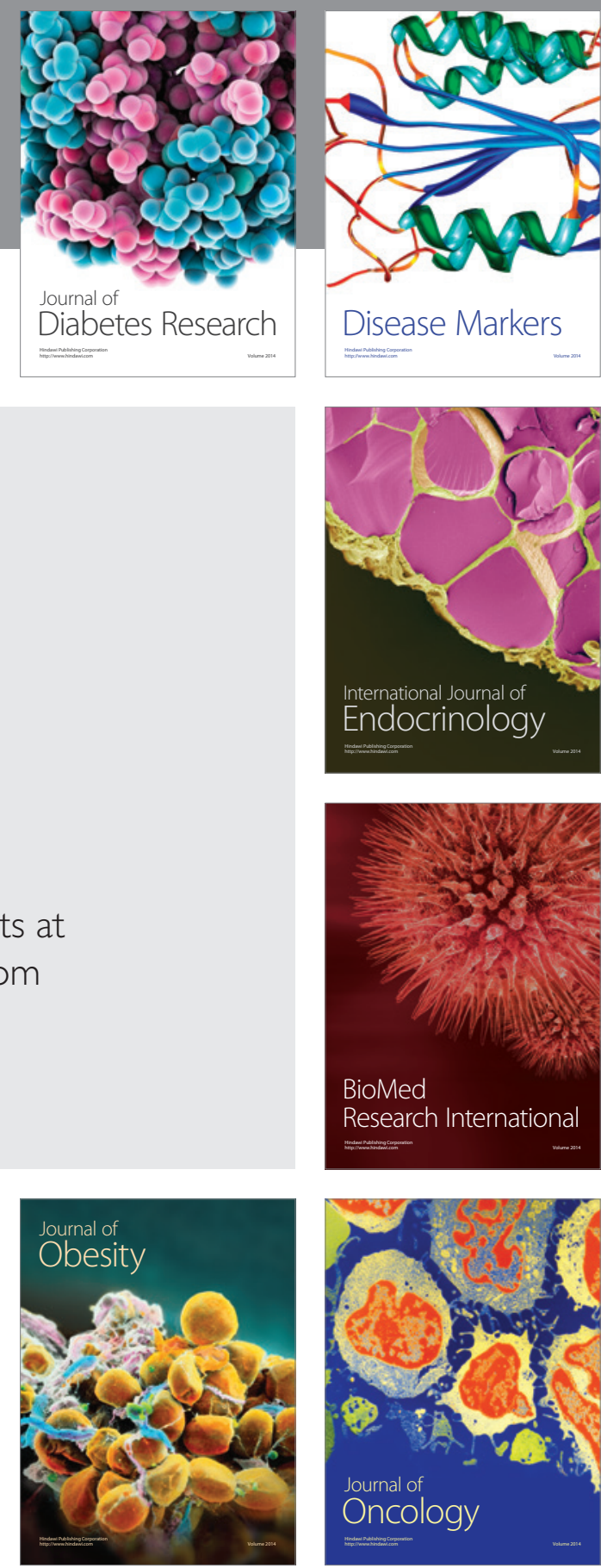

Disease Markers
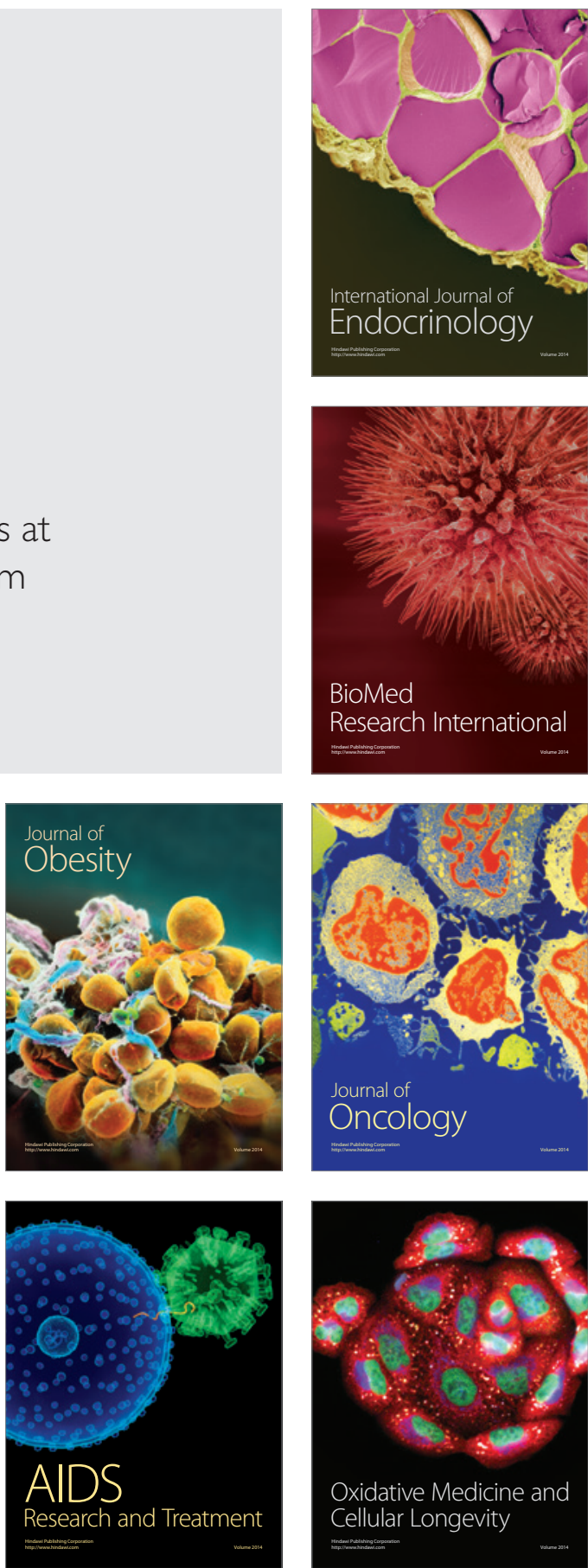